\title{
Signaling Pathways in Cell Polarity
}

\section{Luke Martin McCaffrey ${ }^{1}$ and lan G. Macara ${ }^{2}$}

\author{
${ }^{1}$ Department of Oncology, Rosalind and Morris Goodman Cancer Research Centre, McGill University, Montreal, \\ Quebec, Canada \\ ${ }^{2}$ Department of Microbiology, Center for Cell Signaling, University of Virginia School of Medicine, Charlottesville, \\ Virginia 22908 \\ Correspondence: Igm9c@virginia.edu
}

\section{SUMMARY}

A key function of signal transduction during cell polarization is the creation of spatially segregated regions of the cell cortex that possess different lipid and protein compositions and have distinct functions. Polarity can be initiated spontaneously or in response to signaling inputs from adjacent cells or soluble factors and is stabilized by positive-feedback loops. A conserved group of proteins, the Par proteins, plays a central role in polarity establishment and maintenance in many contexts. These proteins generate and maintain their distinct locations in cells by actively excluding one another from specific regions of the plasma membrane. The Par signaling pathway intersects with multiple other pathways that control cell growth, death, and organization.

\section{Outline}

1 Introduction

2 The Polarization machinery

3 Factors that control polarity protein localization
4 Polarity signaling through PAR3-PAR6-APKC

5 Conclusion

References 


\section{INTRODUCTION}

The asymmetric distribution of proteins, lipids, and RNAs is necessary for cell fate determination, differentiation, and a multitude of specialized cell functions that underlie morphogenesis (St Johnston 2005; Gonczy 2008; Knoblich 2008; Macara and Mili 2008; Martin-Belmonte and Mostov 2008). The establishment of cell polarity can be dissected into three primary processes: (1) breaking symmetry, either through extrinsic cues or stochastically; (2) establishing spatial organization through signal transduction; and (3) amplifying and maintaining the polarized state through feedback loops (Fig. 1). Even single-celled organisms such as budding yeast are polarized and engage sophisticated signaling mechanisms to initiate and organize asymmetric cell divisions. Higher organisms use polarity to build diverse cell types, such as neurons and epithelial cells in animals or stomatal cells in plants. Polarity spatially segregates important cellular functions from one another-for instance, in neurons, it separates synaptic inputs (along dendrites) from signaling outputs (along the axons). Epithelial cell polarity separates the apical membrane, which is specialized for interactions with the external environment, from the baso-lateral membrane, which contacts extracellular matrix or other cell types. In some epithelia a barrier called the tight junction separates the two membrane regions and prevents the intercellular diffusion of material across the epithelial sheet. Once established, cell polarity is often stable for the lifetime of the cell, as in neurons, but it can also be dynamic, for example, during development, when neural crest cells lose their epithelial

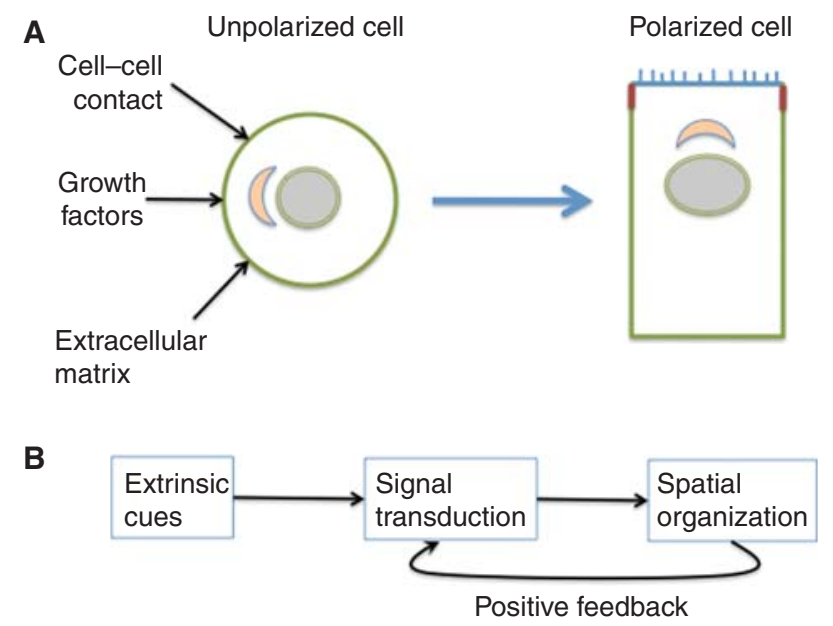

Figure 1. (A) Extrinsic signals normally are responsible for driving cell polarization, although it can also occur spontaneously under certain conditions. $(B)$ Cell polarization is established by signal transduction pathways that spatially segregate different regions of the cell, especially the cell cortex, and this organization is reinforced and maintained by positive-feedback loops. character and become mesenchymal (this is termed the epithelial mesenchymal transition, EMT) (see Neel and Muthuswamy 2012).

A conserved set of proteins called the Par polarity proteins is used in many contexts throughout the animal kingdom-for example, to polarize epithelia, to specify axons versus dendrites in a neuron, and to drive the asymmetric division of a nematode zygote (Fig. 2). These proteins are components of signal transduction pathways and include kinases, GTPases, adaptor proteins, and scaffolds. Additional pathways have evolved that play more specific roles-for instance, in epithelial apical/basal polarization or in planar polarity of epithelial sheets. However, our knowledge of the inputs to and outputs from these pathways and their intersection with other signaling networks remains incomplete. Moreover, despite the high level of conservation at the sequence level, the regulation and cross talk between the polarity proteins and other signaling components vary from one context to another and from one species to another, which complicates the task of dissecting polarity protein function. Nonetheless, rapid progress is being made in our understanding of polarity signaling, which we outline here, with an emphasis on Cdc42 and the Par proteins.

\section{THE POLARIZATION MACHINERY}

\subsection{Symmetry Breaking and Positive-Feedlback Loops}

Symmetry breaking has been studied most intensively in the budding yeast Saccharomyces cerevisiae, which during the cell cycle switches from isotopic growth as a spherical cell to the polarized growth of bud formation before cell division, or to the "schmoo" formation necessary for mating (Slaughter et al. 2009). The key signaling pathway involves the small GTP-binding protein Cdc42 and its various regulators. A positive-feedback loop generates a high local enrichment of GTP-bound Cdc42 at the cell cortex that nucleates actin cables, which recruit more Cdc42 to the site, which, in turn, leads to further actin nucleation (Fig. 3). The initial local enrichment of Cdc42 relies on a separate feedback loop involving a complex of a guanine nucleotide exchange factor (GEF) for Cdc42, called Cdc24, and an adaptor protein (Bem1) (Fig. 3). Cdc42-GTP recruits the adaptor, which, in turn, recruits the GEF, which generates more Cdc42-GTP locally (Butty et al.2002). Note that wild-type haploid yeast cells are never entirely unpolarized, and the new bud always forms adjacent to the bud scar left over from the previous cell cycle.

A pair of membrane-associated proteins near the scar function as the landmark for the new bud and recruit the GEF for a different GTPase, Rsr1, which then recruits Bem1 
A

Kinase

GTPase

GTPase

Adaptor

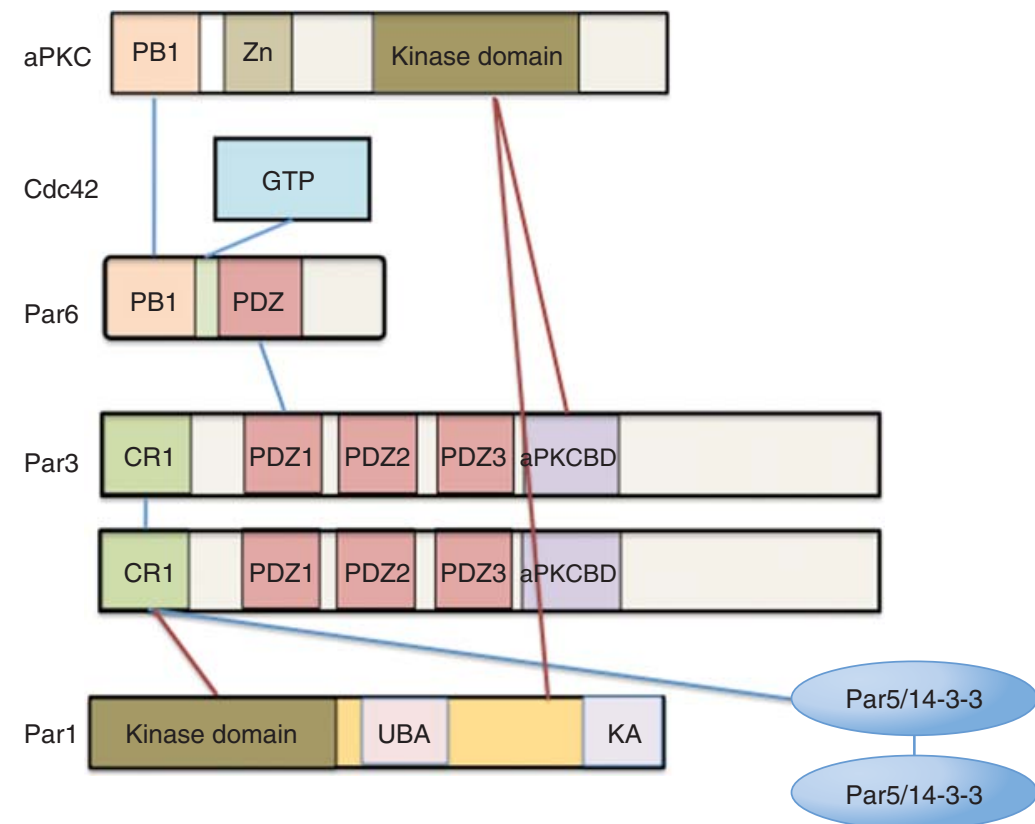

B
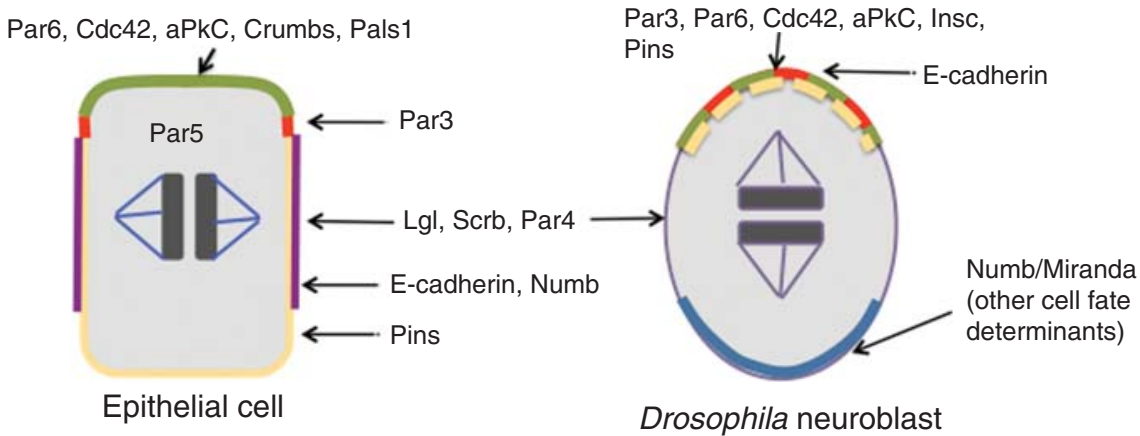

Figure 2. (A) Schematic showing domain structures of Par polarity proteins and their interactions. Phox and Bem1 domain (PB1), forms homodimers and heterodimers; zinc finger domain (Zn); PSD95, Dlg1, ZO-1 domain (PDZ), binds other PDZ domains and carboxy-terminal peptide motifs; conserved region domain (CR1), forms homooligomers; atypical protein kinase $\mathrm{C}$ binding domain (aPKCBD); ubiquitin-binding-associated domain (UBA); kinase-associated domain (KA). (B) The different distributions of these polarity proteins in an epithelial cell and a neuroblast stem cell, together with the localization of other interacting proteins. Note that whereas in neuroblasts all of the polarity proteins form a complex (the "Par complex") at the apical cortex, this is not the case in epithelial cells, in which Par3 is not associated with Par6 and aPKC but is associated instead with the tight junction complex. The orientation of the mitotic spindle is controlled by the Par proteins and is different in neuroblasts (vertical) versus epithelial cells (horizontal). This difference reflects the distinct functions of polarity in the two cell types: segregation of cell fate determinants into only one daughter cell in the neuroblast versus formation of a polarized sheet of cells by the epithelium.

and the Cdc42-specific GEF Cdc24. This GTPase cascade is thought to amplify and stabilize the initial local cue. Interestingly, a GTPase-activating protein (GAP) that inactivates Cdc42 is localized to the old bud site and prevents its reuse in the next cycle (Tong et al. 2007). Other GAPs, which are not localized, inactivate any Cdc42-GTP that diffuses away from the bud site, thereby helping to maintain a focused spot of active $\mathrm{Cdc} 42$ at the correct cortical location. Therefore, local activation and global inactivation of a GTPase, plus cortical landmarks and organization of the actin cytoskeleton, are all used by budding yeast to ensure correct polarization for bud formation.

Do other organisms or cell types use the same mechanisms to drive polarization? Although the details differ, the general concept of reinforcing initial polarity cues with positive-feedback loops is widespread. Perhaps the best 


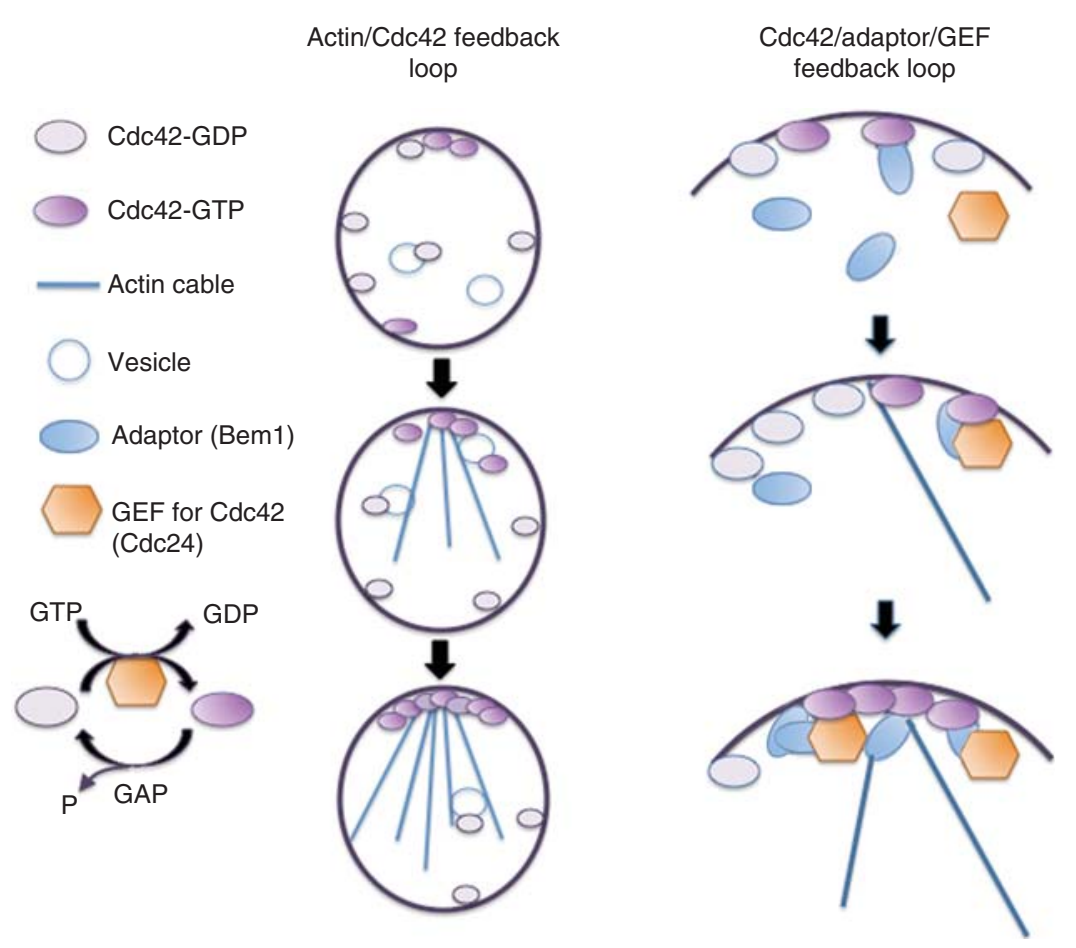

Figure 3. Positive-feedback loops that drive polarization of budding yeast during cell division. Cdc42 can cycle between GDP- and GTP-bound states, catalyzed by guanine nucleotide exchange factors (GEFs) that load GTP onto the protein, and GTPase-activating proteins (GAPs) that stimulate hydrolysis of the bound GTP. In the actin/Cdc42 loop, local enrichment of Cdc42-GTP at the cell cortex triggers nucleation of actin cables, along which vesicles recruit more $\mathrm{Cdc42}$, which nucleates more actin cables. In the Cdc42/adaptor/GEF loop, local enrichment of Cdc42-GTP recruits an adaptor protein (Bem1), which, in turn, recruits a GEF for Cdc42 (Cdc24), which produces more Cdc42-GTP, which can, in turn, recruit more Bem1 and Cdc24.

understood examples are the migration of cells up gradients of a chemical attractant (chemotaxis) in Dictyostelium and in mammalian neutrophils (see Devreotes and Horwitz 2012). These cells use positive feedback to reinforce polarization in the direction of the gradient, but instead of Cdc42, the loop involves PI-3 kinase, the phosphatase PTEN, and a protein kinase, Akt (Charest and Firtel 2006). As in yeast, local activation coupled with global inactivation seems to play an important role in stabilizing polarity (Xiong et al. 2010). Interestingly, Dictyostelium spontaneously and transiently polarizes in random directions even in the absence of any external gradient. This suggests that the detection of the chemotactic signal functions primarily to reinforce and stabilize a preexisting polarity rather than to break symmetry.

\subsection{Par Proteins}

Perhaps the clearest example of symmetry breaking and cell polarization is the fertilization of the Caenorhabditis elegans oocyte. Here the entry of the sperm into the egg breaks symmetry, driving a wave of acto-myosin contractions across the cell cortex and the establishment of an anterior/posterior polarity, exemplified by the distribution of the Par proteins. The par (for "partition-defective") genes were identified in an elegant screen by Jim Priess and Ken Kemphues for maternal-effect genes that are embryonically lethal in C. elegans (Kemphues et al. 1988). Seven genes were identified in the screen, and they are all essential for the first asymmetric cell division of the zygote. Par1 and Par4 (also known as LKB1) are serine/threonine kinases (Guo and Kemphues 1995; Watts et al. 2000); Par2 is a RING-finger domain protein that may function as an E3 ubiquitin ligase (Levitan et al. 1994); Par3 and Par6 are PDZ-domain-containing proteins that have scaffolding or adaptor functions (Etemad-Moghadam et al. 1995; Hung and Kemphues 1999); Par5 is a 14-3-3 protein that binds to phosphorylated serine and threonine residues (Morton et al. 2002); and PKC-3 is an atypical protein kinase C (aPKC) (Fig. 2). With the exception of Par2, all of the Par proteins and aPKC are conserved throughout the Metazoa.

Strikingly, most of these polarity proteins show a polarized distribution within the zygote (Tabuse et al. 1998). Par1 and Par2 are restricted to the posterior of the zygote cortex, whereas Par3, Par6, and aPKC are restricted to the anterior cortex (although they are also present in the 
cytoplasm) (Schneider and Bowerman 2003; Munro 2006). The segregation of the two cortical groups of Par proteins depends on their mutual antagonism, and loss of one Par protein results in escape of the others from their respective domains. In addition, the worm homolog of Lethal Giant Larvae ( $\mathrm{Lgl})$, a polarity protein originally discovered in Drosophila, localizes to the posterior cortex of the worm zygote and helps exclude the Par3-Par6-aPKC complex (Beatty et al. 2010; Hoege et al. 2010). Only Par4 and Par5 are non-polarized, and they are distributed diffusely throughout the cytoplasm, but they are required for the asymmetric distribution of the cortical Par proteins. The mechanisms that underlie this mutual antagonism are described below.

Par3, Par6, and aPKC can form a physical complex (Fig. 2), sometimes called the Par complex (Joberty et al. 2000; Lin et al. 2000; Wodarz et al. 2000), that has been identified in all animal cells that have been examined (Goldstein and Macara 2007). Par6 acts as a regulatory subunit for aPKC. The two proteins are attached to one another through their amino-terminal PB1 domains (Hirano et al. 2005), and this association inhibits the basal activity of aPKC. Par6 can also recruit substrates for phosphorylation (Yamanaka et al. 2001). Interaction of Par6 with Cdc42-GTP induces a conformational switch that relieves the inhibition, enabling the kinase to phosphorylate its substrates. One of these substrates is Par3. Atypical PKC binds through its kinase domain directly to a small region in the carboxy-terminal half of Par3 and phosphorylates S827 within this region (NagaiTamai et al. 2002), which causes the disassociation of the kinase from Par3. However, an additional interaction, between the PDZ domains of Par6 and Par3, can indirectly tether aPKC to Par3 even after S827 phosphorylation. The function of this rather complicated set of interactions is necessary for delivery of aPKC and Par6 to the apical surface of epithelial cells.

Importantly, Par3, Par6, and aPKC do not form a constitutive complex. Their interactions are regulated by multiple protein kinases, by small GTPases, and by competition for other binding partners, including other polarity proteins. These regulators determine the subcellular distribution of the Par proteins. Two striking examples are Drosophila neuroblasts and epithelial cells (Fig. 2). In the neuroblasts, Par3, Par6, and aPKC all localize together at the apical crescent, in a complex with two other proteins, Inscuteable and Partner of Inscuteable (Pins), which control spindle orientation during mitosis. This clustering of polarity proteins is independent of the phosphorylation of Par3 by aPKC. In contrast, only aPKC and Par6 are apical in epithelial cells, whereas Par3 segregates to the lateral/apical boundary (or to tight junctions in mammalian epithelial cells) (Fig. 2) (Izumi et al. 1998; Joberty et al. 2000). Moreover, the localization of aPKC and Par6 to the apical cortex depends on the ability of aPKC to phosphorylate Par3. As described above, the phosphorylation partially disengages aPKC from Par3; but the two proteins remain attached through Par6. An epithelium-specific polarity protein at the apical membrane, called Crumbs, outcompetes Par6, displacing Par3 (Morais-de-Sa et al. 2010). In this way, Par3 is completely disengaged, and the Par6-aPKC complex is retained at the apical cortex.

\subsection{Intercellular Junctions}

Intercellular junctions are a universal feature of multicellular organisms. They provide the glue that binds cells together into tissues and organs, but also provide for the transmission of signals between adjacent cells. Many types of adhesive proteins have evolved, but the most widespread are the cadherins - transmembrane proteins that form calcium-dependent homophilic interactions between adjacent cells. The intracellular domains of cadherins bind to catenins, which perform multiple functions, including stabilizing adhesive clusters at cell-cell interfaces, interacting with the actin cytoskeleton, and serving as signaling platforms that are coupled to many of the known signal transduction networks within the cell, including the Par polarity proteins. Vertebrate epithelia and endothelia also possess tight junctions, which form both a barrier between cells and a fence between the apical and lateral domains of the plasma membrane within each cell. The fence prevents the free diffusion of membrane proteins and lipids between these two domains, thereby helping to maintain apical/ baso-lateral polarity. Tight junctions are composed principally of transmembrane proteins called claudins, but-as is true for adhesive junctions - there are numerous additional proteins that associate with the claudins to form the junctional structures.

Despite the important role of intercellular junctions in polarity, cell polarization is not dependent on their existence. Baas et al. (2004) have shown that single intestinal cells can be induced to polarize simply by the activation of Par4, in the complete absence of attachment to any neighboring cell. Moreover, Drosophila epithelial cells do not possess tight junctions, yet are able to segregate apical from lateral proteins as efficiently as do their mammalian counterparts.

\section{FACTORS THAT CONTROL POLARITY PROTEIN LOCALIZATION}

The Par proteins provide critical spatial information during polarization, to identify different regions of the cell cortex. The localization of polarity proteins is therefore central to their biological functions. Protein localization 
often involves distinct steps that can include transport, delivery, anchoring at the destination, and active exclusion from other areas of the cell. Transport can simply involve passive diffusion, or directed movement along the cytoskeleton. Alternatively, the mRNA encoding the protein might be transported to the destination, where it is locally translated. Anchors can include phospholipids, cytoskeletal elements, or more specific protein complexes.

\subsection{Membrane Attachment via Phospholipids}

All of the Par proteins except for Par4 and Par5, plus other polarity proteins including Lgl, Scribble, Dlg, Pals1, Patj, and Crumbs, are found predominantly at the cell cortex. Crumbs is a transmembrane protein that tethers Patj, Pals1, and Lin7 to the apical cortex. Par3 contains a conserved basic amino acid motif in the carboxy-terminal half of the protein that can bind directly to phosphoinositides (Krahn et al. 2010), which is both necessary and sufficient for association with membranes. An additional phosphoinositide-binding mechanism has been proposed for this protein, through phosphoinositide binding to its PDZ2 domain (Wu et al. 2007). No other polarity protein is known to contain lipid-binding motifs, but Par4 is farne- sylated at its carboxyl terminus, and this hydrophobic posttranslational modification could facilitate association with membranes.

\subsection{Oligomerization}

The amino-terminal conserved region 1 (CR1) is necessary for self-association of Par3 into higher-order complexes (Fig. 2) (Benton and Johnston 2003a; Mizuno et al. 2003; Feng et al. 2007). It is essential but not sufficient for membrane attachment. How the oligomerization of Par3 maintains the protein at the plasma membrane is unclear, but oligomerization might complement weak phosphoinositide binding by increasing avidity (Fig. 4).

\subsection{Anchoring to Membrane Proteins}

Enrichment and retention in a specific region of the cell cortex is frequently mediated by direct interactions with transmembrane proteins. Pals1 and Par6 can both bind directly to the carboxy-terminal sequence of Crumbs, via their PDZ domains. Par6 and Patj can also associate indirectly with Crumbs through Pals1. The recruitment of Par3 to tight junctions in mammalian epithelial cells is mediated,

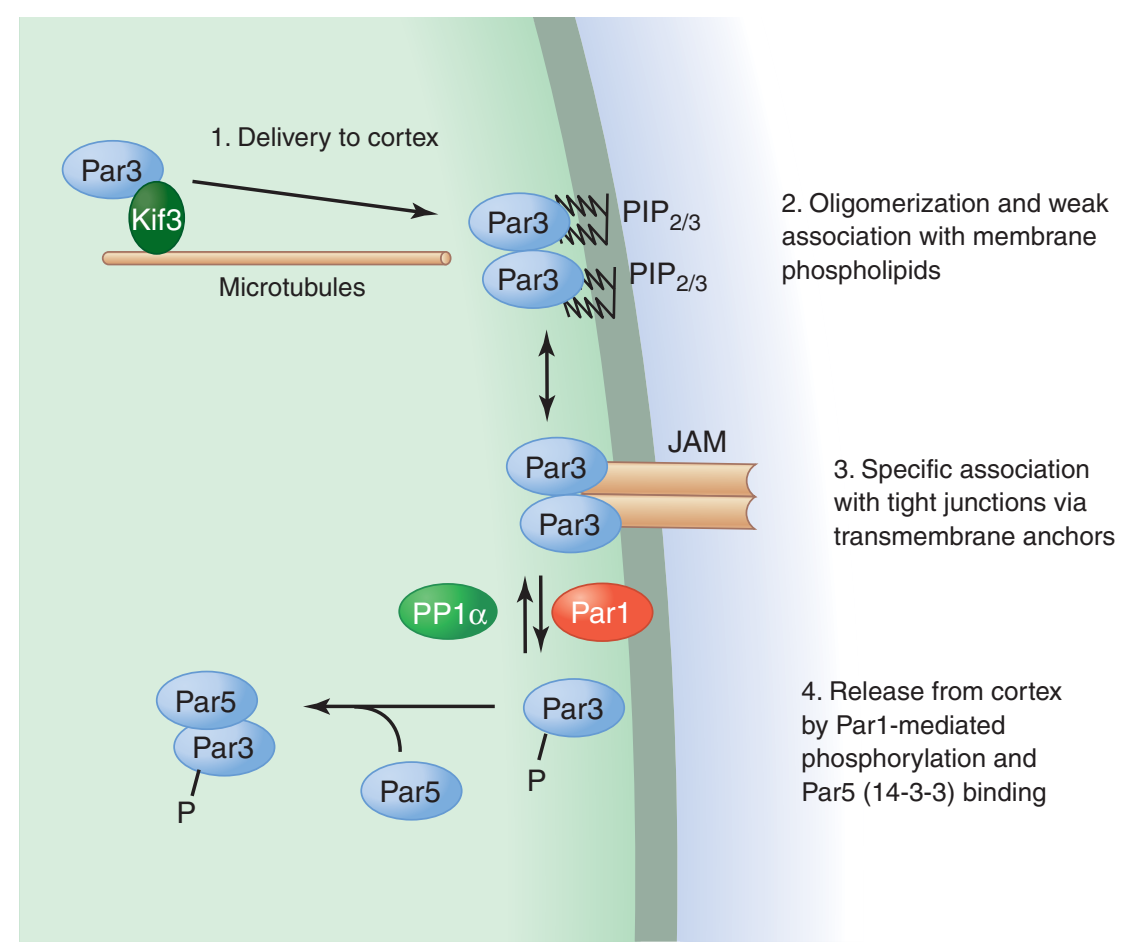

Figure 4. Mechanisms for the transport, cortical association, and anchoring of Par3 in mammalian cells. It is not yet known if all of these mechanisms operate in any one cell type, and additional processes, such as RNA localization, might play roles in certain circumstances. Junctional adhesion molecule (JAM) is shown as an example of a transmembrane protein to which Par3 can be anchored, but others exist, such as the neurotrophin receptor, p75NTR, in mammalian Schwann cells (Chan et al. 2006). PP1 $\alpha$ is a phosphatase. 
at least in part, through association between the first PDZ domain of Par3 and the carboxyl terminus of junction adhesion molecules (JAMs) (Fig. 4) (Ebnet et al. 2000; Itoh et al. 2001). Because Par6 also binds to the first PDZ domain of Par3, the associations with JAM and Par6 are mutually exclusive. A similar mechanism occurs in the mouse neuroepithelium, where Par3 is recruited to newly formed intercellular junctions through a direct interaction with nectin 1 or nectin 3 (Takekuni et al. 2003). In the Drosophila wing disc epithelium, Par3 is also recruited to junctions through its PDZ domains, by interaction with the adherens junction proteins $\beta$-catenin and Echinoid, an immunoglobulin-domain transmembrane protein (Wei et al. 2005). In embryonic epithelium, Par3 instead associates with E-cadherin (Harris and Peifer 2005). Thus, different tissues use distinct mechanisms to organize the spatial distribution of Par3 and other polarity proteins.

\subsection{Localized mRNA Translation}

RNA localization and local translation are important drivers of cell polarization in several situations and have been intensively studied in the Drosophila oocyte, in budding yeast, and in vertebrate neurons. The mRNAs for two epithelial-specific polarity proteins, Crumbs and Pals1 (also called Stardust), are enriched near the apical surface in Drosophila epithelial cells (Horne-Badovinac and Bilder 2008; Li et al. 2008). Why localize RNAs? One potential function is to regulate translation, perhaps in response to extracellular signals, or to cell density changes. As an example, the Par3 mRNA—but not that of Par6 or aPKC—is transported out along the axons of mammalian motor neurons, where it can be locally translated in response to stimulation of the neurons by nerve growth factor (NGF), a process that is essential for NGF-dependent axon outgrowth (Hengst et al. 2009).

\subsection{Active Exclusion}

None of the mechanisms described above stably anchors Par proteins at the plasma membrane. Cortical Par proteins are highly dynamic in the C. elegans zygote, rapidly exchanging with cytoplasmic pools and undergoing lateral diffusion along the plasma membrane (Goehring et al. 2011). Lgl protein is also highly dynamic in Drosophila embryonic cells (Mayer et al. 2005). Therefore, the targeting and retention mechanisms described above are insufficient to maintain their polarized distribution within the cell. Active mechanisms drive the segregation of polarity proteins into different cortical domains and maintain their asymmetry. As mentioned above, the Par3-Par6-aPKC complex is often localized in a complementary pattern to that of Par1, and through mutual phosphorylation reactions, the two kinases, aPKC and Par1, exclude each other from their respective regions of the cortex. Par1 directly phosphorylates Par3 on S144 (equivalent to S151 in Drosophila) (Benton and Johnston 2003b; Hurd et al. 2003a) near CR1, the region necessary for oligomerization of Par3. The phosphorylated S144/151 residue acts as a docking site for Par5 (14-3-3), which might reduce oligomerization and thereby destabilize membrane association of Par3 (Fig. 4). This mechanism can therefore exclude Par3 from cortical regions that contain Par1. The phosphorylation and binding of Par5 (14-3-3) to Par3 can be reversed by protein phosphatase $1 \alpha(\mathrm{PP} 1 \alpha)$, allowing recycling of Par3 to appropriate cortical sites.

Conversely, aPKC can phosphorylate Parl, which both inhibits Parl kinase activity and disassociates it from the plasma membrane (Fig. 5A). Two distinct mechanisms have been identified, one in which aPKC directly phosphorylates Par1 on T595 (Hurov et al. 2004) and an indirect mechanism by which aPKC activates protein kinase $\mathrm{D}$ (PKD), which then phosphorylates Par1 on S400 (Watkins et al. 2008). Phosphorylation of T595 reduces the kinase activity and displaces Parl from the membranes. Furthermore, phosphorylation of S400 recruits Par5 (14-3-3), which displaces Par1 from the membrane.

The C. elegans aPKC can also phosphorylate Par2 and exclude it from the anterior cortical domain of the zygote, whereas Par2 in the posterior domain recruits Par1 to phosphorylate and exclude Par3 (Hao et al. 2006).

The spatial distributions of many downstream effectors of the Par signaling pathway are also controlled by phosphorylation. For example, the cell fate determinants Numb and Miranda, the polarity protein Lgl, and the spindle orientation factor Pins (called LGN in mammals), are all removed from the plasma membrane by aPKC-dependent phosphorylation (Fig. 5B) (Betschinger et al. 2003; Hao et al. 2006; Smith et al. 2007; Atwood and Prehoda 2009). Pins associates with the cell cortex in mitosis, by binding to Gai subunits, where it functions to attach astral microtubules, which orient the mitotic spindle. In epithelial tissues, normal organization is often dictated by the ability of cells to divide in the plane of the epithelial sheet, but not perpendicular to the sheet. To this end, apical aPKC phosphorylates any Pins that diffuses into the apical region, resulting in the recruitment of Par5 (14-3-3), which disengages Pins from Gai. In this way, Pins is excluded from the apical cortex, preventing astral microtubule attachment and perpendicular orientation of mitosis. Pins also orients the mitotic spindles in Drosophila stem cells and in some mammalian progenitors. Similar mechanisms, involving not only aPKC and Par1 but other protein kinases that target Par5 (14-3-3) consensus sites, probably also exist. 
A

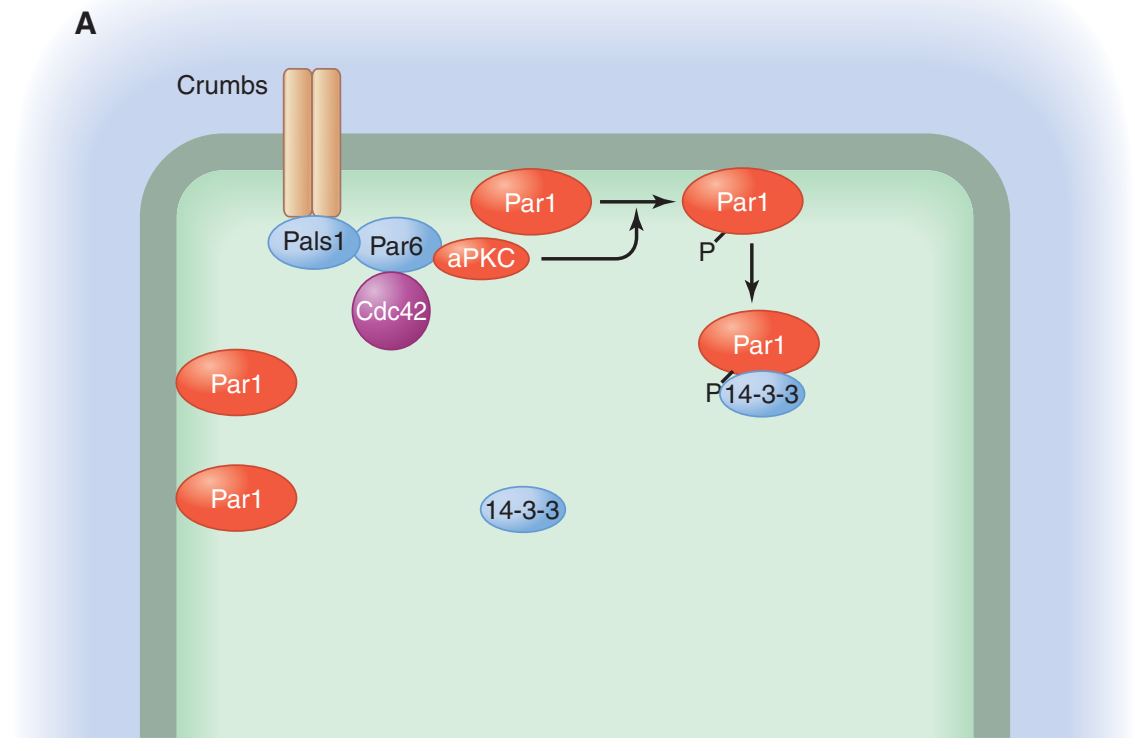

B

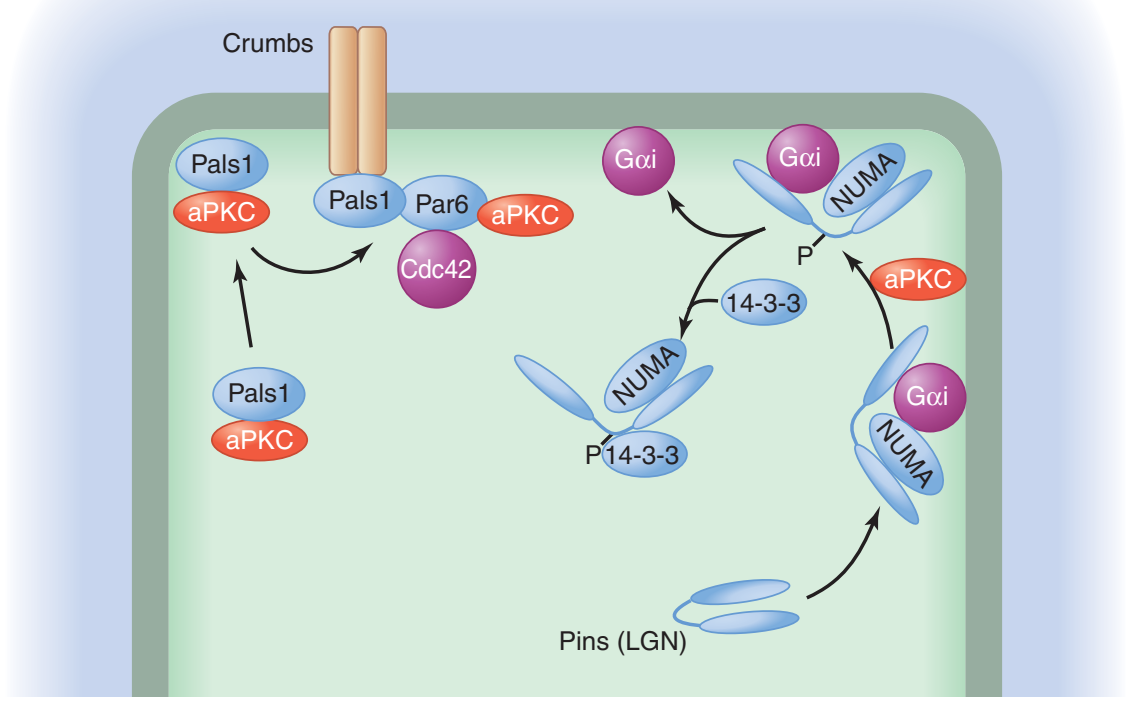

Figure 5. Active exclusion from cortical domains. A common mechanism for the establishment of discrete cortical regions of the cell occurs through the active removal of unwanted proteins from within a particular region. A kinase within the region phosphorylates the protein, resulting in the association of Par5 (14-3-3), which displaces the protein from the cell cortex. (A) Parl is restricted to the lateral membranes in epithelial cells. Any Parl that strays onto the apical surface is phosphorylated by aPKC, which recruits Par5 (14-3-3), causing its disassociation from the membrane. $(B)$ aPKC at the apical surface of an epithelial cell phosphorylates any Pins (also known as LGN) protein that binds to G $\alpha$ i within this domain. Association of the phosphorylated Pins with 14-3-3 triggers its dissociation from Gai. Because phosphorylation does not occur at the basolateral membrane, Pins can remain associated with this region of the cortex. Pins is diffuse in the cytoplasm in interphase cells and can only associate with Gai at the cell cortex after it has undergone a conformational switch triggered by the binding of NuMA, a nuclear protein that is released in mitosis. Also shown in this schematic is the recruitment by Par3 of aPKC to the apical surface, where the aPKC is disengaged and binds to the Crumbs-Pals1-Par6 complex. The apical aPKC is activated by the binding of Cdc42-GTP to Par6. 
The mechanism underlying exclusion of Numb from the apical region of progenitor cells in Drosophila has been worked out in considerable detail. At the onset of mitosis, Aurora-A phosphorylates Par6 within the PB1 domain that binds to aPKC (Fig. 2), releasing Par6 and relieving its inhibition of aPKC (Wirtz-Peitz et al. 2008). The activated aPKC phosphorylates Lgl, which causes it to dissociate from the Par6-aPKC complex and allows the complex to interact with Par3. Par3 then acts to recruit Numb as a substrate for aPKC. Phosphorylation of Numb by aPKC causes it to be released from the cell cortex (Smith et al. 2007; Wirtz-Peitz et al. 2008). Because the Par complex is initially asymmetrically distributed, the loss of Numb occurs at only one side of the mitotic cell; thus, one daughter will inherit Numb while the other does not. Interestingly, Lgl seems here to function as a buffer, to suppress the phosphorylation of Numb until the appropriate time in the cell cycle. The recruitment of Numb by Par3 seems to be an evolutionarily conserved function, because in migrating mammalian fibroblasts, the same mechanism is used to release Numb from the cell cortex and regulates the internalization of integrins (Nishimura and Kaibuchi 2007).

\section{POLARITY SIGNALING THROUGH PAR3-PAR6-APKC}

\subsection{Polarity Signaling through Small GTPases}

Actin filaments and microtubules are the two major asymmetric components of cells. Both are vectorial polymers, and their organization is, therefore, of fundamental importance to cell polarization. This organization is dynamic and is highly regulated by signaling networks that respond to external and internal cues. Central to these signaling networks are the Rho family GTPases (Fig. 3), which regulate and are regulated by polarity proteins.

Cdc42 is a pivotal component of the polarity machinery in yeast and is conserved throughout the metazoa. Dominant-negative Cdc42 mutants disrupt polarized migration in mammalian fibroblasts (Nobes and Hall 1999), and Cdc42-GTP binds to Par6, providing a mechanism by which the GTPase can control cell polarization. Par6 contains a partial CRIB domain, a motif conserved among most Cdc42 effectors. This domain interacts with a region of the GTPase that undergoes a GTP-dependent switch in conformation (Garrard et al. 2003). Binding of Cdc42-GTP to Par6 relieves the inhibition of aPKC activity by Par6 (Yamanaka et al. 2001). In addition, the cytoplasmic tail of the receptor tyrosine kinase ephrin B1 competes with Cdc42 for binding to Par6, blocking tight junction formation (Lee et al. 2008). Tyrosine phosphorylation of ephrin B1 releases it from Par6. In this way, signaling through tyrosine kinase receptors could affect aPKC activity and consequently cell polarity decisions.

In addition to counteracting the inhibition of aPKC by Par6, Cdc42 can also recruit the Par6-aPKC complex to specific regions of the cell cortex where Cdc42 is activated. For example, in Drosophila neuroblasts mutant for Cdc42, Par6-aPKC is mislocalized to the cytoplasm (Atwood et al. 2007), and depletion of Cdc42 from mammalian epithelial cells can partially mislocalize aPKC from the apical cortex (Martin-Belmonte et al. 2007). A positive-feedback loop probably reinforces the positioning of these proteins, because robust $\mathrm{Cdc} 42$ localization in the neuroblasts also requires Par6. In the C. elegans zygote, Cdc42 is not essential for the initial anterior enrichment of Par6, although the asymmetry is lost later, during the first cell division, which suggests that other factors set up the polarity (Aceto et al. 2006). In mammalian epithelial cells, Par6 localization to the apical surface probably requires its association with Pals 1 and/or Crumbs, rather than Cdc42 (Gao et al. 2002; Hurd et al. 2003b).

Another small GTPase, Rho1, helps organize the polarity of the C. elegans zygote. The RhoGEF Ectl is excluded from the posterior cortex, which restricts Rho-GTP production to the anterior end of the zygote (Motegi and Sugimoto 2006), where it stimulates myosin contractility. This contraction generates a cortical actin flow, translocating Par6, aPKC, Par3, and Cdc42 to the anterior end of the zygote. Cdc42-GTP then maintains this distribution of the Par proteins.

The Rho GTPase may play a distinct role in mammalian cells by controlling the association of Par3 with Par6-aPKC (Fig. 6). ROCK, a protein kinase downstream from RhoA, can phosphorylate Par3 on T833, adjacent to the aPKCbinding site in the carboxyl terminus of Par3, and this phosphorylation blocks the association with aPKC (Nakayama et al. 2008). However, aPKC can also phosphorylate ROCK, which suppresses its association with epithelial junctions. Because ROCK phosphorylates the myosin light chain and activates actomyosin contractility, this represents an additional polarity mechanism (Ishiuchi and Takeichi 2011).

\subsection{Rho GTPases as Downstream Effectors of Par3-Par6-aPKC}

The carboxy-terminal region of Par3 can bind to a Rac GEF called Tiam1 (Chen and Macara 2005; Mertens et al. 2005; Nishimura et al. 2005; Zhang and Macara 2006). Par3 sequesters Tiam1 to prevent inappropriate activation of Rac (Chen and Macara 2005; Zhang and Macara 2006). Loss of Par3 causes an increase in Rac-GTP levels, which results in a misorganization of actin filaments at the cell cortex. A 


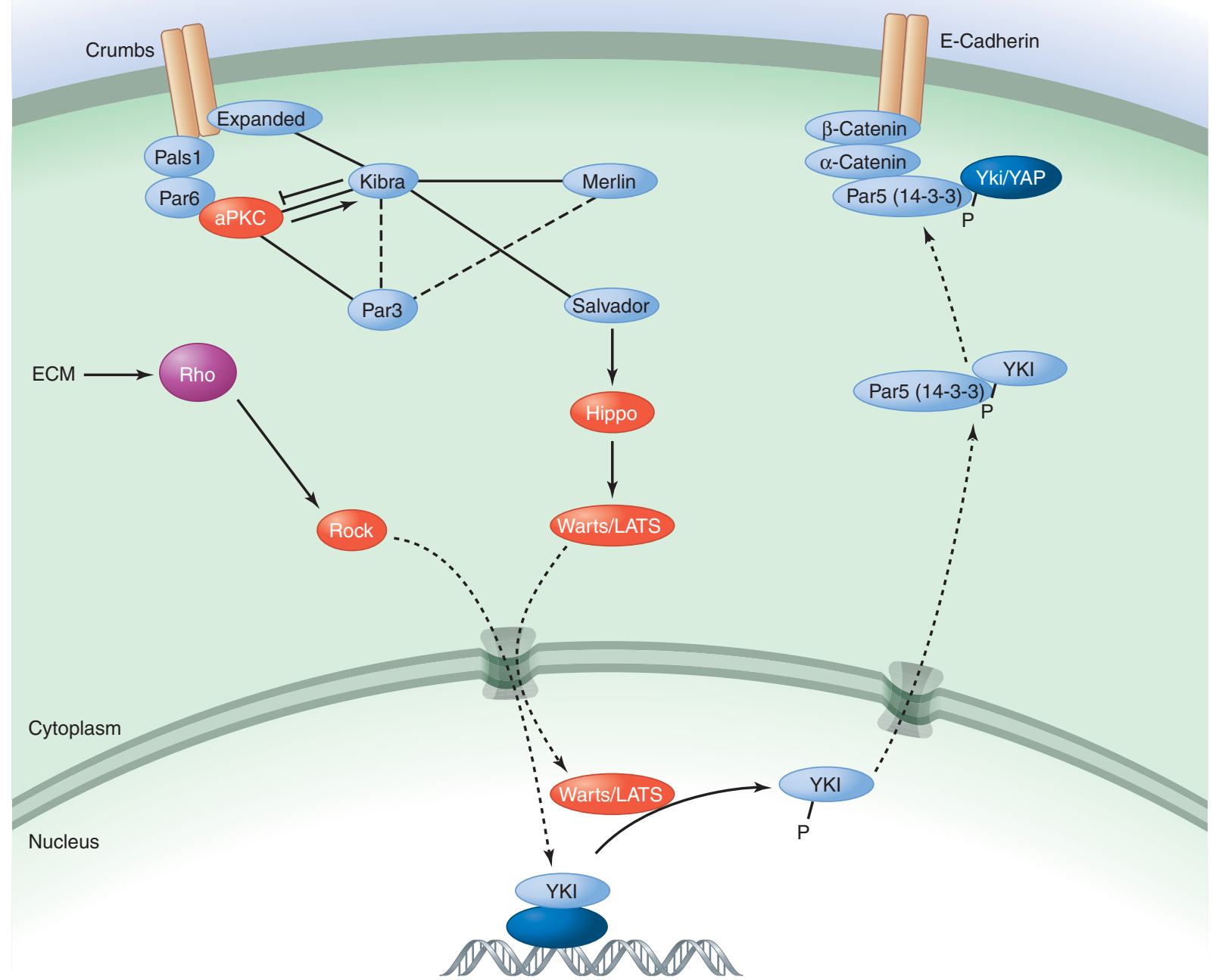

Figure 6. Interaction map showing potential links between the Par proteins and components of the Hippo pathway. A signaling cascade involving Salvador, Hippo, and Warts controls phosphorylation and nuclear localization of the transcription factors Yorkie (YKI) and TAZ to regulate epithelial growth. Epithelial integrity is monitored by celladhesion complexes (E-cadherin, $\alpha$-catenin) and by the Par and Crumbs polarity complexes through the adaptor Kibra. The extracellular matrix (ECM) also has an impact on YKI nuclear localization through the Rho GTPase, independently of the Hippo pathway.

similar mechanism operates in the notum epithelium of Drosophila, where Par3 inhibits Sif, the fly homolog of Tiam1, to restrict filopodium formation to basal regions of the cell (Georgiou and Baum 2010). In other cell types, Par3 might recruit Tiam1 to sites within the cell where Rac needs to be activated. In such cases, loss of Par3 might reduce Rac activation at these sites (Pegtel et al. 2007).

Par6 can also regulate RhoA activity. By associating with aPKC, Par6 can activate a RhoGAP called p190, thereby reducing Rho-GTP levels (Zhang and Macara 2008). The link between Par6-aPKC and the p190 RhoGAP is unknown, but the pathway is important for controlling synapse density in hippocampal neurons. Elevated expression of Par6 increases dendritic spine density, whereas silencing of Par6 reduces spine density.

A second, different mechanism by which Par6 can affect Rho is through association with Smad-ubiquitin regulatory factor 1 (Smurf1), an E3 ligase that down-regulates the TGF $\beta$ signaling pathway (Fig. 4). In addition to targeting Smads for degradation, Smurf1 can also ubiquitylate RhoA (Wang et al. 2003). TGF $\beta$ type II receptor can bind to and phosphorylate Par6 on a conserved carboxy-terminal residue (S345) (Ozdamar et al. 2005). This stimulates the association of Par6 (or aPKC) with Smurf1, which mediates 
the localized ubiquitylation and destruction of RhoA. In mammary NMuMG cells, loss of RhoA can cause the dissolution of tight junctions and an EMT (Wang et al. 2003). However, these effects might be cell type specific because, for example, in MDCK cells, dominant-negative RhoA expression had no effect on tight junctions (Bruewer et al. 2004).

\subsection{Cross Talk between Wnt Signaling and Polarity Proteins}

Planar cell polarity (PCP) signaling establishes directional asymmetry at the tissue level rather than at the cellular level (as occurs in apical/basal polarization or in the asymmetric divisions of some stem cells). PCP signaling establishes the directionality of wing hair orientation in Drosophila, for example, and the orientation of cilia in the outer hair cells of the mammalian cochlea. It is also essential for the oriented migration of cell sheets during gastrulation. PCP is stimulated by Wnt ligands that activate seven-transmembrane-span receptors of the Frizzled family (Simons and Mlodzik 2008). Other transmembrane proteins, including Vangl and Flamingo (also called Celsr), are also essential for PCP signaling. Downstream from these proteins, an adaptor called Dishevelled (Dvl) can recruit a GEF to activate RhoA (Tsuji et al. 2010), which stimulates the downstream kinase ROCK. As described above, ROCK phosphorylates Par3, in addition to the myosin light chain and other targets. Dvl is itself a target for phosphorylation by the Par1 polarity protein and can directly associate with aPKC (Sun et al. 2001; Ossipova et al. 2005). The association with aPKC stabilizes and activates the kinase and has been implicated in axonal differentiation and polarized migration of mammalian cells (Schlessinger et al. 2007; Zhang et al. 2007). Moreover, the Drosophila Frizzled receptor is phosphorylated and inhibited by aPKC, which is recruited to Frizzled through another polarity protein, Patj (Djiane et al. 2005). Thus, aPKC mediates multiple signaling connections between PCP components. Whether its binding partners Cdc42 and Par6 participate in PCP regulation remains to be determined.

Another apical/basal polarity protein, Scribble, has also been implicated in PCP. The mechanism remains obscure, but it interacts genetically and physically with Vangl, which, in turn, can bind to the extracellular domain of Frizzled, perhaps enabling non-cell-autonomous signaling between neighboring cells (Courbard et al. 2009). Signaling downstream from Scribble is poorly understood and requires the carboxyl terminus of the protein, including the third and fourth PDZ domains, which bind to Vangl. Control of api$\mathrm{cal} /$ basal polarity by Scribble in Drosophila, in contrast, does not require any of the PDZ domains (Zeitler et al. 2004).

\subsection{Connections between the Hippo Pathway and Polarity Signaling}

The Hippo pathway was first discovered in Drosophila as a central regulator of organ size (Grusche et al. 2010). It controls the balance between proliferation and apoptosis in flies and mammals and involves a protein kinase cascade that ultimately phosphorylates and inactivates the transcriptional coactivators Yorkie (YKI, also known as Yap1) and TAZ (Fig. 6) (Hariharan 2012).

Phospho-Yap1 is sequestered at adherens junctions through association with $\alpha$-catenin. This catenin can function as a tumor suppressor, and in the epidermis, loss of $\alpha$ catenin results in the nuclear accumulation of YKI and increased cell proliferation (Schlegelmilch et al. 2011; Silvis et al. 2011). How cell density controls the $\alpha$-catenin-YKI interaction remains unclear, but another Hippo pathway component, Merlin, also binds directly to $\alpha$-catenin and is required for stable adherens junction formation (Gladden et al. 2010). Merlin couples $\alpha$-catenin to Par3 during junction maturation in keratinocytes, which might be important for the apical positioning of tight junctions relative to the adherens junctions. In addition, Par5 (14-3-3) is required for the association of $\alpha$-catenin with YKI. Merlin might in some way regulate the association of YKI-Par5 with $\alpha$-catenin.

Remarkably, mechanical forces also regulate YKI (Fig. 6). Increasing the stiffness of the extracellular matrix activates Rho and its downstream kinase ROCK-through an unknown mechanism - which drives the nuclear accumulation and activation of YKI (Dupont et al. 2011). This pathway seems to be entirely separate from the canonical Hippo pathway but provides a direct mechanism through which the physical environment can reprogram gene expression. Whether $\alpha$-catenin is involved in this pathway, through interactions with actin, remains to be determined.

Apical/basal polarity proteins also interact with components of the Hippo pathway (Fig. 6). For example, the Drosophila protein Expanded binds to the intracellular domain of Crumbs (Chen et al. 2010; Grzeschik et al. 2010; Ling et al. 2010; Robinson et al. 2010). Expanded is a FERMdomain protein distantly related to Merlin. Changes in the level of Crumbs expression cause a mislocalization of Expanded and are sufficient to induce hyperproliferation of epithelial cells in Drosophila (Lu and Bilder 2005). The vertebrate homolog of Expanded has not yet been unambiguously identified, however, and it remains unknown whether a similar signaling pathway operates in mammalian epithelial cells. The wiring might be somewhat different, because in mouse epithelial cell lines, Crumbs3dependent apico-basal polarization leads to sequestration of SMADs in the cytoplasm through the Hippo pathway, 
which inhibits TGF $\beta$ signaling and EMT (Varelas et al. 2010), but there is no evidence of a link to TGF- $\beta$ in Drosophila.

An important component of the Hippo pathway is Kibra, which binds to many pathway components, including Expanded, Merlin, Warts, Hippo, and Salvador, but how these interactions are regulated remains unclear. Kibra also associates with the Par complex and localizes to tight junctions and the apical membrane (Yoshihama et al. 2010). Kibra is a substrate for aPKC phosphorylation (Büther et al. 2004), but Kibra can also negatively regulate aPKC activity to control exocytosis of apical membrane components (Yoshihama et al. 2010). A similar mechanism might function in cell migration, during which an aPKC-Kibra-exocyst complex regulates focal adhesion dynamics at the leading edge by recruiting the MAP kinase ERK (Rosse et al. 2009). It seems likely that these connections could play important roles in the misorganization, overgrowth, and invasion of epithelial cancers.

\subsection{Polarity Signaling and Cancer}

The majority of human cancers arise from epithelial cells, and tumorigenesis is commonly believed to involve a loss of apical/basal polarity (Brugge 2012). In particular, cells at the invasive fronts of carcinomas often express proteins associated with a mesenchymal phenotype, such as vimentin and Snail, whereas epithelial proteins such as E-cadherin and Crumbs are either lost or mislocalized away from the cell cortex. Some of these changes in expression are caused by reduced expression of micro-RNAs in the MiR-200 family, which suppress the expression of a transcription factor, ZEB1.ZEB1, in turn, suppresses the expression of epithelial genes, including E-cadherin and the polarity genes $\mathrm{Crb3}$ (a Crumbs homolog), Lgl, and Patj (Brabletz and Brabletz 2010). Because only the outermost layers of tumor cells in a carcinoma usually show mesenchymal characteristics, they are probably induced by interactions of the tumor cells with the surrounding stroma, but the mechanisms involved remain unclear (Vidal et al. 2010). Cells that have undergone an EMT are more motile, more invasive, and less adherent (see Neel and Muthuswamy 2012), and might contribute to dissemination of tumors throughout the body and establishment of metastases. However, it is important to note that there is very little evidence of a role for the polarity machinery in human cancer. Although several polarity proteins, including Scribble and Lgl, have tumor suppressor behavior in Drosophila, their role in human cancers remains ill defined (Wu et al. 2010). Moreover, it remains to be established whether loss of polarity is an essential aspect of malignancy. Epithelial cells could escape from their tissue of origin by mechanisms independent of classical EMT, including changes in spindle orientation during mitosis and collective migration of clusters of cells (Rorth 2009).

\section{CONCLUSION}

Understanding cell polarization is one of the major goals of cell biology and will inevitably have a broad impact on research into diseases such as cancer and neurological degeneration. A complicated web of signaling systems surrounds and intersects with the polarity machinery, yet we still understand very little about what the Par proteins do, how they are localized, how their various interactions are regulated, and which signaling components operate in which contexts. After all, the organization of a polarized cell is a formidably complicated process that involves cytoskeletal remodeling, membrane traffic, RNA localization, and protein complex assembly and disassembly, with feedback to gene expression and protein turnover. It is conceivable that the Par proteins participate in all of these processes, either directly or indirectly. It is worth remembering, however, that although the polarity machinery can work in a cell-autonomous fashion, the Par genes do not exist in any unicellular organism, which suggests that a key role for the Par proteins is to facilitate, mediate, or interpret cell-cell and cell-matrix interactions. The tissue context might, therefore, be expected to modulate Par protein functions. It will be interesting to determine whether regulation of these interactions controls morphogenesis and to what extent differential Par function contributes to phenotypic variation both between different cell types in one organism and between species.

\section{REFERENCES}

* Reference is also in this collection.

Aceto D, Beers M, Kemphues KJ. 2006. Interaction of PAR-6 with CDC42 is required for maintenance but not establishment of PAR asymmetry in C. elegans. Dev Biol 299: 386-397.

Atwood SX. Prehoda KE. 2009. aPKC phosphorylates Miranda to polarize fate determinants during neuroblast asymmetric cell division. Curr Biol 19: $723-729$.

Atwood SX, Chabu C, Penkert RR, Doe CQ, Prehoda KE. 2007. Cdc42 acts downstream of Bazooka to regulate neuroblast polarity through Par-6 aPKC. J Cell Sci 120: 3200-3206.

Baas AF, Kuipers J, van der Wel NN, Batlle E, Koerten HK, Peters PJ, Clevers HC. 2004. Complete polarization of single intestinal epithelial cells upon activation of LKB1 by STRAD. Cell 116: 457-466.

Beatty A, Morton D, Kemphues K. 2010. The C. elegans homolog of Drosophila Lethal giant larvae functions redundantly with PAR-2 to maintain polarity in the early embryo. Development 137: 3995-4004.

Benton R, Johnston DS. 2003a. A conserved oligomerization domain in Drosophila Bazooka/PAR-3 is important for apical localization and epithelial polarity. Curr Biol 13: 1330-1334.

Benton R, Johnston DS. 2003b. Drosophila PAR-1 and 14-3-3 inhibit Bazooka/PAR-3 to establish complementary cortical domains in polarized cells. Cell 115: 691-704. 
Betschinger J, Mechtler K, Knoblich JA. 2003. The Par complex directs asymmetric cell division by phosphorylating the cytoskeletal protein Lgl. Nature 422: 326-330.

Brabletz S, Brabletz T. 2010. The ZEB/miR-200 feedback loop-a motor of cellular plasticity in development and cancer? EMBO Rep 11: $670-677$.

Bruewer M, Hopkins AM, Hobert ME, Nusrat A, Madara JL. 2004. RhoA, Rac1, and Cdc42 exert distinct effects on epithelial barrier via selective structural and biochemical modulation of junctional proteins and F-actin. Am J Physiol Cell Physiol 287: C327-C335.

* Brugge J. 2012. Signaling in cancer. Cold Spring Harb Perspect Biol doi: 10.1101/cshperspect.a006098.

Büther K, Plaas C, Barnekow A, Kremerskothen J. 2004. KIBRA is a novel substrate for protein kinase Cל. Biochem Biophys Res Commun 317: $703-707$.

Butty AC, Perrinjaquet N, Petit A, Jaquenoud M, Segall JE, Hofmann K, Zwahlen C, Peter M. 2002. A positive feedback loop stabilizes the guanine-nucleotide exchange factor $\mathrm{Cdc} 24$ at sites of polarization. EMBO J 21: 1565-1576.

Chan JR, Jolicoeur C, Yamauchi J, Elliott J, Fawcett JP, Ng BK, Cayouette M. 2006. The polarity protein Par-3 directly interacts with $\mathrm{p} 75^{\mathrm{NTR}}$ to regulate myelination. Science 314: 832-836.

Charest PG, Firtel RA. 2006. Feedback signaling controls leading-edge formation during chemotaxis. Curr Opin Genet Dev 16: 339-347.

Chen X, Macara IG. 2005. Par-3 controls tight junction assembly through the Rac exchange factor Tiam1. Nat Cell Biol 7: 262-269.

Chen CL, Gajewski KM, Hamaratoglu F, Bossuyt W, Sansores-Garcia L, Tao C, Halder G. 2010. The apical-basal cell polarity determinant Crumbs regulates Hippo signaling in Drosophila. Proc Natl Acad Sci 107: $15810-15815$.

Courbard JR, Djiane A, Wu J, Mlodzik M. 2009. The apical/basal-polarity determinant Scribble cooperates with the PCP core factor Stbm/ Vang and functions as one of its effectors. Dev Biol 333: 67-77.

* Devreotes P, Horwitz AF. 2012. Cell migration and chemotaxis. Cold Spring Harb Perspect Biol doi: 10.1101/cshperspect.a005959.

Djiane A, Yogev S, Mlodzik M. 2005. The apical determinants aPKC and dPatj regulate Frizzled-dependent planar cell polarity in the Drosophila eye. Cell 121: 621-631.

Dupont S, Morsut L, Aragona M, Enzo E, Giulitti S, Cordenonsi M, Zanconato F, Le Digabel J, Forcato M, Bicciato S, et al. 2011. Role of YAP/TAZ in mechanotransduction. Nature 474: 179-183.

Ebnet K, Schulz CU, Meyer Zu Brickwedde MK, Pendl GG, Vestweber D. 2000. Junctional adhesion molecule interacts with the PDZ domaincontaining proteins AF-6 and ZO-1. J Biol Chem 275: 27979-27988.

Etemad-Moghadam B, Guo S, Kemphues KJ. 1995. Asymmetrically distributed PAR-3 protein contributes to cell polarity and spindle alignment in early C. elegans embryos. Cell 83: 743-752.

Feng W, Wu H, Chan LN, Zhang M. 2007. The Par-3 NTD adopts a PB1like structure required for Par-3 oligomerization and membrane localization. EMBO J 26: 2786-2796.

Gao L, Joberty G, Macara IG. 2002. Assembly of epithelial tight junctions is negatively regulated by Par6. Curr Biol 12: 221-225.

Garrard SM, Capaldo CT, Gao L, Rosen MK, Macara IG, Tomchick DR. 2003. Structure of Cdc42 in a complex with the GTPase-binding domain of the cell polarity protein, Par6. EMBO J 22: 1125-1133.

Georgiou M, Baum B. 2010. Polarity proteins and Rho GTPases cooperate to spatially organise epithelial actin-based protrusions. J Cell Sci 123: $1089-1098$.

Gladden AB, Hebert AM, Schneeberger EE, McClatchey AI. 2010. The NF2 tumor suppressor, Merlin, regulates epidermal development through the establishment of a junctional polarity complex. Dev Cell 19: $727-739$.

Goehring NW, Hoege C, Grill SW, Hyman AA. 2011. PAR proteins diffuse freely across the anterior-posterior boundary in polarized C. elegans embryos. J Cell Biol 193: 583-594.

Goldstein B, Macara IG. 2007. The PAR proteins: Fundamental players in animal cell polarization. Dev Cell 13: 609-622.
Gonczy P. 2008. Mechanisms of asymmetric cell division: Flies and worms pave the way. Nat Rev Mol Cell Biol 9: 355-366.

Grusche FA, Richardson HE, Harvey KF. 2010. Upstream regulation of the Hippo size control pathway. Curr Biol 20: R574-R582.

Grzeschik NA, Parsons LM, Allott ML, Harvey KF, Richardson HE. 2010. Lgl, aPKC, and Crumbs regulate the Salvador/Warts/Hippo pathway through two distinct mechanisms. Curr Biol 20: 573-581.

Guo S, Kemphues KJ. 1995. par-1, a gene required for establishing polarity in C. elegans embryos, encodes a putative Ser/Thr kinase that is asymmetrically distributed. Cell 81: 611-620.

Hao Y, Boyd L, Seydoux G. 2006. Stabilization of cell polarity by the C. elegans RING protein PAR-2. Dev Cell 10: 199-208.

* Hariharan I. 2012. Wnt signaling. Cold Spring Harb Perspect Biol doi: $10.1101 /$ cshperspect.a011288.

Harris TJ, Peifer M. 2005. The positioning and segregation of apical cues during epithelial polarity establishment in Drosophila. J Cell Biol 170: 813-823.

Hengst U, Deglincerti A, Kim HJ, Jeon NL, Jaffrey SR. 2009. Axonal elongation triggered by stimulus-induced local translation of a polarity complex protein. Nat Cell Biol 11: 1024-1030.

Hirano Y, Yoshinaga S, Takeya R, Suzuki NN, Horiuchi M, Kohjima M, Sumimoto H, Inagaki F. 2005. Structure of a cell polarity regulator, a complex between atypical PKC and Par6 PB1 domains. J Biol Chem 280: $9653-9661$.

Hoege C, Constantinescu AT, Schwager A, Goehring NW, Kumar P, Hyman AA. 2010. LGL can partition the cortex of one-cell Caenorhabditis elegans embryos into two domains. Curr Biol 20: 1296-1303.

Horne-Badovinac S, Bilder D. 2008. Dynein regulates epithelial polarity and the apical localization of stardust A mRNA. PLoS Genet 4: e8.

Hung TJ, Kemphues KJ. 1999. PAR-6 is a conserved PDZ domain-containing protein that colocalizes with PAR-3 in Caenorhabditis elegans embryos. Development 126: 127-135.

Hurd TW, Fan S, Liu C-J, Kweon HK, Hakansson K, Margolis B. 2003a. Phosphorylation-dependent binding of 14-3-3 to the polarity protein Par3 regulates cell polarity in mammalian epithelia. Curr Biol 13: $2082-2090$

Hurd TW, Gao L, Roh MH, Macara IG, Margolis B. 2003b. Direct interaction of two polarity complexes implicated in epithelial tight junction assembly. Nat Cell Biol 5: 137-142.

Hurov JB, Watkins JL, Piwnica-Worms H. 2004. Atypical PKC phosphorylates PAR-1 kinases to regulate localization and activity. Curr Biol 14: $736-741$

Ishiuchi T, Takeichi M. 2011. Willin and Par3 cooperatively regulate epithelial apical constriction through aPKC-mediated ROCK phosphorylation. Nat Cell Biol 13: 860-866.

Itoh M, Sasaki H, Furuse M, Ozaki H, Kita T, Tsukita S. 2001. Junctional adhesion molecule (JAM) binds to PAR-3: A possible mechanism for the recruitment of PAR-3 to tight junctions. J Cell Biol 154: 491-497.

Izumi Y, Hirose T, Tamai Y, Hirai S, Nagashima Y, Fujimoto T, Tabuse Y, Kemphues KJ, Ohno S. 1998. An atypical PKC directly associates and colocalizes at the epithelial tight junction with ASIP, a mammalian homologue of Caenorhabditis elegans polarity protein PAR-3. J Cell Biol 143: 95-106.

Joberty G, Petersen C, Gao L, Macara IG. 2000. The cell-polarity protein Par6 links Par3 and atypical protein kinase C to Cdc42. Nat Cell Biol 2: 531-539.

Kemphues KJ, Priess JR, Morton DG, Cheng NS. 1988. Identification of genes required for cytoplasmic localization in early C. elegans embryos. Cell 52: 311-320.

Knoblich JA. 2008. Mechanisms of asymmetric stem cell division. Cell 132: $583-597$.

Krahn MP, Buckers J, Kastrup L, Wodarz A. 2010. Formation of a Bazoo$\mathrm{ka}-$ Stardust complex is essential for plasma membrane polarity in epithelia. J Cell Biol 190: 751-760.

Lee HS, Nishanian TG, Mood K, Bong YS, Daar IO. 2008. EphrinB1 controls cell-cell junctions through the Par polarity complex. Nat Cell Biol 10: 979-986. 
Levitan DJ, Boyd L, Mello CC, Kemphues KJ, Stinchcomb DT. 1994. par2, a gene required for blastomere asymmetry in Caenorhabditis elegans, encodes zinc-finger and ATP-binding motifs. Proc Natl Acad Sci 91: $6108-6112$.

Li Z, Wang L, Hays TS, Cai Y. 2008. Dynein-mediated apical localization of crumbs transcripts is required for Crumbs activity in epithelial polarity. J Cell Biol 180: 31-38.

Lin D, Edwards AS, Fawcett JP, Mbamalu G, Scott JD, Pawson T. 2000. A mammalian PAR-3-PAR-6 complex implicated in Cdc42/Rac1 and aPKC signalling and cell polarity. Nat Cell Biol 2: 540-547.

Ling C, Zheng Y, Yin F, Yu J, Huang J, Hong Y, Wu S, Pan D. 2010. The apical transmembrane protein Crumbs functions as a tumor suppressor that regulates Hippo signaling by binding to Expanded. Proc Natl Acad Sci 107: 10532-10537.

Lu H, Bilder D. 2005. Endocytic control of epithelial polarity and proliferation in Drosophila. Nat Cell Biol 7: 1232-1239.

Macara IG, Mili S. 2008. Polarity and differential inheritance-universal attributes of life? Cell 135: 801-812.

Martin-Belmonte F, Mostov K. 2008. Regulation of cell polarity during epithelial morphogenesis. Curr Opin Cell Biol 20: 227-234.

Martin-Belmonte F, Gassama A, Datta A, Yu W, Rescher U, Gerke V, Mostov K. 2007. PTEN-mediated apical segregation of phosphoinositides controls epithelial morphogenesis through Cdc42. Cell 128: 383-397.

Mayer B, Emery G, Berdnik D, Wirtz-Peitz F, Knoblich JA. 2005. Quantitative analysis of protein dynamics during asymmetric cell division. Curr Biol 15: 1847-1854.

Mertens AE, Rygiel TP, Olivo C, van der Kammen R, Collard JG. 2005. The Rac activator Tiam1 controls tight junction biogenesis in keratinocytes through binding to and activation of the Par polarity complex. J Cell Biol 170: 1029-1037.

Mizuno K, Suzuki A, Hirose T, Kitamura K, Kutsuzawa K, Futaki M, Amano Y, Ohno S. 2003. Self-association of PAR-3-mediated by the conserved $\mathrm{N}$-terminal domain contributes to the development of epithelial tight junctions. J Biol Chem 278: 31240-31250.

Morais-de-Sa E, Mirouse V, St Johnston D. 2010. aPKC phosphorylation of Bazooka defines the apical/lateral border in Drosophila epithelial cells. Cell 141: 509-523.

Morton DG, Shakes DC, Nugent S, Dichoso D, Wang W, Golden A, Kemphues KJ. 2002. The Caenorhabditis elegans par-5 gene encodes a 14-3-3 protein required for cellular asymmetry in the early embryo. Dev Biol 241: 47-58.

Motegi F, Sugimoto A. 2006. Sequential functioning of the ECT-2 RhoGEF, RHO-1 and CDC-42 establishes cell polarity in Caenorhabditis elegans embryos. Nat Cell Biol 8: 978-985.

Munro EM. 2006. PAR proteins and the cytoskeleton: A marriage of equals. Curr Opin Cell Biol 18: 86-94.

Nagai-Tamai Y, Mizuno K, Hirose T, Suzuki A, Ohno S. 2002. Regulated protein-protein interaction between aPKC and PAR-3 plays an essential role in the polarization of epithelial cells. Genes Cells 7: $1161-1171$.

Nakayama M, Goto TM, Sugimoto M, Nishimura T, Shinagawa T, Ohno S, Amano M, Kaibuchi K. 2008. Rho-kinase phosphorylates PAR-3 and disrupts PAR complex formation. Dev Cell 14: 205-215.

* Neel B, Muthuswamy S. 2012. Cell differentiation. Cold Spring Harb Perspect Biol doi: 10.1101/cshperspect.a005884.

Nishimura T, Kaibuchi K. 2007. Numb controls integrin endocytosis for directional cell migration with aPKC and PAR-3. Dev Cell 13: $15-28$.

Nishimura T, Yamaguchi T, Kato K, Yoshizawa M, Nabeshima YI, Ohno S, Hoshino M, Kaibuchi K. 2005. PAR-6-PAR-3 mediates Cdc42-induced Rac activation through the Rac GEFs STEF/Tiam1. Nat Cell Biol 7: 270-277.

Nobes CD, Hall A. 1999. Rho GTPases control polarity, protrusion, and adhesion during cell movement. J Cell Biol 144: 1235-1244.
Ossipova O, Dhawan S, Sokol S, Green JB. 2005. Distinct PAR-1 proteins function in different branches of Wnt signaling during vertebrate development. Dev Cell 8: 829-841.

Ozdamar B, Bose R, Barrios-Rodiles M, Wang HR, Zhang Y, Wrana JL. 2005. Regulation of the polarity protein Par6 by TGF $\beta$ receptors controls epithelial cell plasticity. Science 307: 1603-1609.

Pegtel DM, Ellenbroek SI, Mertens AE, van der Kammen RA, de Rooij J, Collard JG. 2007. The par-tiam 1 complex controls persistent migration by stabilizing microtubule-dependent front-rear polarity. Curr Biol 17: 1623-1634.

Robinson BS, Huang J, Hong Y, Moberg KH. 2010. Crumbs regulates Salvador/Warts/Hippo signaling in Drosophila via the FERM-domain protein Expanded. Curr Biol 20: 582-590.

Rorth P. 2009. Collective cell migration. Annu Rev Cell Dev Biol 25: 407-429.

Rosse C, Formstecher E, Boeckeler K, Zhao Y, Kremerskothen J, White MD, Camonis JH, Parker PJ. 2009. An aPKC-exocyst complex controls paxillin phosphorylation and migration through localised JNK1 activation. PLoS Biol 7: e1000235.

Schlegelmilch K, Mohseni M, Kirak O, Pruszak J, Rodriguez JR, Zhou D, Kreger BT, Vasioukhin V, Avruch J, Brummelkamp TR, et al. 2011. Yap1 acts downstream of $\alpha$-catenin to control epidermal proliferation. Cell 144: 782-795.

Schlessinger K, McManus EJ, Hall A. 2007. Cdc42 and noncanonical Wnt signal transduction pathways cooperate to promote cell polarity. J Cell Biol 178: 355-361.

Schneider SQ, Bowerman B. 2003. Cell polarity and the cytoskeleton in the Caenorhabditis elegans zygote. Annu Rev Genet 37: 221-249.

Silvis MR, Kreger BT, Lien WH, Klezovitch O, Rudakova GM, Camargo FD, Lantz DM, Seykora JT, Vasioukhin V. 2011. $\alpha$-Catenin is a tumor suppressor that controls cell accumulation by regulating the localization and activity of the transcriptional coactivator Yap1. Sci Signal 4: ra33.

Simons M, Mlodzik M. 2008. Planar cell polarity signaling: From fly development to human disease. Annu Rev Genet 42: 517-540.

Slaughter BD, Smith SE, Li R. 2009. Symmetry breaking in the life cycle of the budding yeast. Cold Spring Harb Perspect Biol 1: a003384.

Smith CA, Lau KM, Rahmani Z, Dho SE, Brothers G, She YM, Berry DM, Bonneil E, Thibault P, Schweisguth F, et al. 2007. aPKC-mediated phosphorylation regulates asymmetric membrane localization of the cell fate determinant Numb. Embo J 26: 468-480.

St Johnston D. 2005. Moving messages: The intracellular localization of mRNAs. Nat Rev Mol Cell Biol 6: 363-375.

Sun TQ, Lu B, Feng JJ, Reinhard C, Jan YN, Fantl WJ, Williams LT. 2001. PAR-1 is a Dishevelled-associated kinase and a positive regulator of Wnt signalling. Nat Cell Biol 3: 628-636.

Tabuse Y, Izumi Y, Piano F, Kemphues KJ, Miwa J, Ohno S. 1998. Atypical protein kinase C cooperates with PAR-3 to establish embryonic polarity in Caenorhabditis elegans. Development 125: 3607-3614.

Takekuni K, Ikeda W, Fujito T, Morimoto K, Takeuchi M, Monden M, Takai Y. 2003. Direct binding of cell polarity protein PAR-3 to cell-cell adhesion molecule nectin at neuroepithelial cells of developing mouse. J Biol Chem 278: 5497-5500.

Tong Z, Gao XD, Howell AS, Bose I, Lew DJ, Bi E. 2007. Adjacent positioning of cellular structures enabled by a Cdc42 GTPase-activating protein-mediated zone of inhibition. J Cell Biol 179: 1375-1384.

Tsuji T, Ohta Y, Kanno Y, Hirose K, Ohashi K, Mizuno K. 2010. Involvement of p114-RhoGEF and Lfc in Wnt-3a- and Dishevelled-induced RhoA activation and neurite retraction in N1E-115 mouse neuroblastoma cells. Mol Biol Cell 21: 3590-3600.

Varelas X, Samavarchi-Tehrani P, Narimatsu M, Weiss A, Cockburn K, Larsen BG, Rossant J, Wrana JL. 2010. The Crumbs complex couples cell density sensing to Hippo-dependent control of the TGF- $\beta$ SMAD pathway. Dev Cell 19: 831-844.

Vidal M, Salavaggione L, Ylagan L, Wilkins M, Watson M, Weilbaecher K, Cagan R. 2010. A role for the epithelial microenvironment at tumor 
boundaries: Evidence from Drosophila and human squamous cell carcinomas. Am J Pathol 176: 3007-3014.

Wang HR, Zhang Y, Ozdamar B, Ogunjimi AA, Alexandrova E, Thomsen GH, Wrana JL. 2003. Regulation of cell polarity and protrusion formation by targeting RhoA for degradation. Science 302: 17751779.

Watkins JL, Lewandowski KT, Meek SE, Storz P, Toker A, Piwnica-Worms H. 2008. Phosphorylation of the Par-1 polarity kinase by protein kinase D regulates 14-3-3 binding and membrane association. Proc Natl Acad Sci 105: 18378-18383.

Watts JL, Morton DG, Bestman J, Kemphues KJ. 2000. The C. elegans par4 gene encodes a putative serine-threonine kinase required for establishing embryonic asymmetry. Development 127: 1467-1475.

Wei SY, Escudero LM, Yu F, Chang LH, Chen LY, Ho YH, Lin CM, Chou CS, Chia W, Modolell J, et al. 2005. Echinoid is a component of adherens junctions that cooperates with DE-Cadherin to mediate cell adhesion. Dev Cell 8: 493-504.

Wirtz-Peitz F, Nishimura T, Knoblich JA. 2008. Linking cell cycle to asymmetric division: Aurora-A phosphorylates the Par complex to regulate Numb localization. Cell 135: 161-173.

Wodarz A, Ramrath A, Grimm A, Knust E. 2000. Drosophila atypical protein kinase $\mathrm{C}$ associates with Bazooka and controls polarity of epithelia and neuroblasts. J Cell Biol 150: 1361-1374.

Wu H, Feng W, Chen J, Chan LN, Huang S, Zhang M. 2007. PDZ domains of Par-3 as potential phosphoinositide signaling integrators. Mol Cell 28: 886-898.
Wu M, Pastor-Pareja JC, Xu T. 2010. Interaction between Ras(V12) and scribbled clones induces tumour growth and invasion. Nature 463: $545-548$.

Xiong Y, Huang CH, Iglesias PA, Devreotes PN. 2010. Cells navigate with a local-excitation, global-inhibition-biased excitable network. Proc Natl Acad Sci 107: 17079-17086.

Yamanaka T, Horikoshi Y, Suzuki A, Sugiyama Y, Kitamura K, Maniwa R, Nagai Y, Yamashita A, Hirose T, Ishikawa H, et al. 2001. PAR-6 regulates aPKC activity in a novel way and mediates cell-cell contact-induced formation of the epithelial junctional complex. Genes Cells 6: $721-731$

Yoshihama Y, Sasaki K, Horikoshi Y, Suzuki A, Ohtsuka T, Hakuno F, Takahashi S, Ohno S, Chida K. 2010. KIBRA suppresses apical exocytosis through inhibition of aPKC kinase activity in epithelial cells. Curr Biol 21: 705-711.

Zeitler J, Hsu CP, Dionne H, Bilder D. 2004. Domains controlling cell polarity and proliferation in the Drosophila tumor suppressor Scribble. J Cell Biol 167: 1137-1146.

Zhang H, Macara IG. 2006. The polarity protein PAR-3 and TIAM1 cooperate in dendritic spine morphogenesis. Nat Cell Biol 8: 227-237.

Zhang H, Macara IG. 2008. The PAR-6 polarity protein regulates dendritic spine morphogenesis through p190 RhoGAP and the Rho GTPase. Dev Cell 14: 216-226.

Zhang X, Zhu J, Yang GY, Wang QJ, Qian L, Chen YM, Chen F, Tao Y, Hu HS, Wang T, et al. 2007. Dishevelled promotes axon differentiation by regulating atypical protein kinase C. Nat Cell Biol 9: 743-754. 


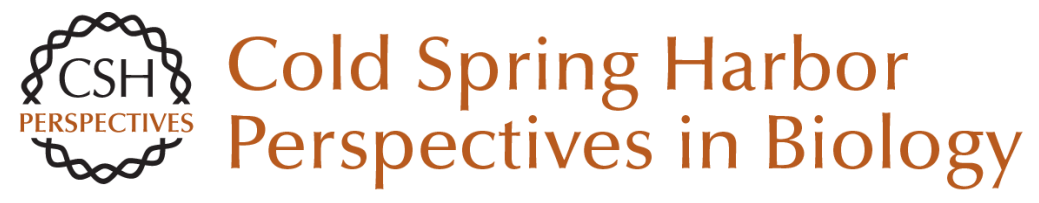

\section{Signaling Pathways in Cell Polarity}

Luke Martin McCaffrey and Ian G. Macara

Cold Spring Harb Perspect Biol 2012; doi: 10.1101/cshperspect.a009654 originally published online May 2, 2012

\section{Subject Collection Signal Transduction}

Cell Signaling and Stress Responses Gökhan S. Hotamisligil and Roger J. Davis

Protein Regulation in Signal Transduction Michael J. Lee and Michael B. Yaffe

Synaptic Signaling in Learning and Memory Mary B. Kennedy

Vertebrate Reproduction Sally Kornbluth and Rafael Fissore

Signaling in Lymphocyte Activation Doreen Cantrell

Signaling in Muscle Contraction Ivana Y. Kuo and Barbara E. Ehrlich

Toll-Like Receptor Signaling Kian-Huat Lim and Louis M. Staudt

Signaling Pathways that Regulate Cell Division Nicholas Rhind and Paul Russell

\section{Second Messengers}

Alexandra C. Newton, Martin D. Bootman and John D. Scott

Signals and Receptors Carl-Henrik Heldin, Benson Lu, Ron Evans, et al.

Cell Death Signaling Douglas $R$. Green and Fabien Llambi

Signaling Networks that Regulate Cell Migration Peter Devreotes and Alan Rick Horwitz

Signaling Networks: Information Flow, Computation, and Decision Making Evren U. Azeloglu and Ravi lyengar

Signal Transduction: From the Atomic Age to the Post-Genomic Era Jeremy Thorner, Tony Hunter, Lewis C. Cantley, et al.

Signaling by the TGF $\beta$ Superfamily Jeffrey L. Wrana

Subversion of Cell Signaling by Pathogens Neal M. Alto and Kim Orth

For additional articles in this collection, see http://cshperspectives.cshlp.org/cgi/collection/

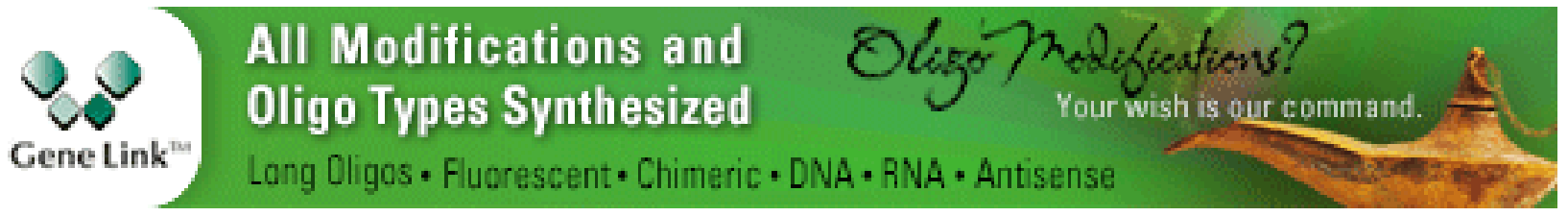

Copyright (C) 2012 Cold Spring Harbor Laboratory Press; all rights reserved 